\title{
Low Temperature Carburization
}

\section{Synonyms}

Expanded austenite; Low temperature colossal supersaturation; Low temperature interstitial hardening; Paraequilibrium carburization; S-phase

\section{Definition}

Low temperature gas phase carburization is a novel surface engineering process developed by the Swagelok Co. (Solon, $\mathrm{OH}$ ), which enhances the surface hardness and wear resistance of stainless steels and Ni and Co-based alloys, while also preserving corrosion resistance (Michal et al. 2006a; Martin et al. 2007). Low temperature carburization and conventional carburization are similar in that carbon is diffused from the carbonaceous atmosphere into the surface region of an alloy to achieve significant interstitial hardening; however, these processes differ with respect to the carburization temperatures. Conventional carburization of stainless steel would be carried out at $900^{\circ} \mathrm{C}$ or higher, where the high mobility of both carbon and substitutional solutes make the formation of carbides unavoidable. This results in a loss of corrosion resistance due to the local depletion of chromium in grain boundaries regions ("sensitization"), which in turn hinders the formation of a protective corrosion-resistant passive oxide film (Hall and Briant 1984). In contrast, the low temperature carburization process operates under conditions that kinetically prevent the formation of carbides. However, sufficient mobility of interstitial carbon is available under these conditions to generate a useful $\sim 25 \mu \mathrm{m}$ thick "case." Furthermore, carburization under these paraequilibrium conditions results in a metastable "colossal" carbon supersaturation.

Low temperature carburization actually enhances the corrosion resistance of the treated alloys (Martin et al. 2007), as well as the surface hardness and wear resistance. Ongoing research is currently investigating the efficacy of interstitial hardening via low temperature carburization for other alloy systems, including duplex, martensitic, and ferritic stainless steels.

\section{Scientific Fundamentals}

\section{Low Temperature Carburization}

Several different low temperature carburization processes have been developed including atmospheric gas phase carburization and plasma carburization. The low temperature carburization treatment of $316 \mathrm{~L}$ austenitic stainless steel practiced by the Swagelok Co. (Williams et al. 2000a, b, 2002, 2003) (Fig. 1) entails a gaseous HCl "activation" step, in which the spontaneously formed passive film is removed to enable efficient uptake of carbon, following which the alloy is exposed to a $\mathrm{CO}$ (or hydrocarbon) ambient of very high carbon activity at $1 \mathrm{~atm}$. pressure, thus generating a large driving force for inward diffusion of carbon into the steel. After a second activation step and a second exposure to a high carbon activity ambient, the $\mathrm{CO}$ content is gradually reduced to a carbon activity of $\sim 1$. The total process for $316 \mathrm{~L}$ austenitic stainless steel is completed in about $30 \mathrm{~h}$, and routinely achieves a surface hardness greater than $\approx 10 \mathrm{GPa}$, and a $\approx 25$ $\mu \mathrm{m}$ thick carbon-rich hardened near-surface region (the case). 


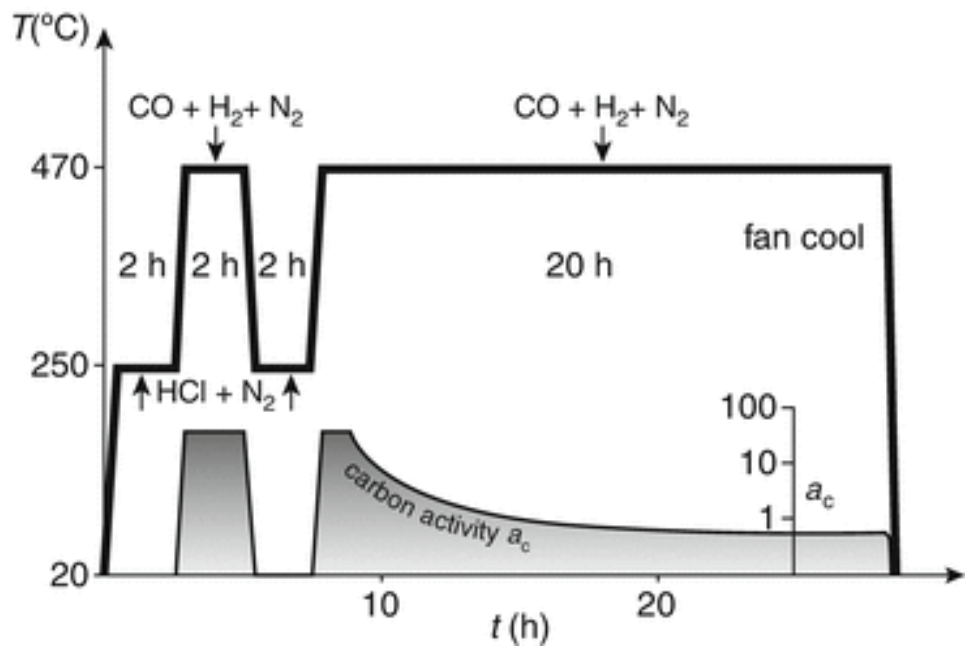

Low Temperature Carburization, Fig. 1 General Swagelok Co. gas-phase low temperature carburization process for 316L austenitic stainless steel (Martin et al. 2007)

\section{Paraequilibrium Carburization and Kinetic Limitations of Carbide Formation}

As illustrated by the time-temperature-transformation (TTT) diagram for AISI 316 stainless steel (Fig. 2), the low temperature carburization process temperature is below the nose of the C-curve for formation of $\mathrm{M}_{23} \mathrm{C}_{6}($ Michal et al. 2006b). In this temperature region, diffusion of substitutional solutes, such as $\mathrm{Cr}$ and $\mathrm{Ni}$, is limited, rendering them essentially immobile, whereas the mobility of carbon is high enough to allow inward transport from the carbon-rich atmosphere, and formation of a hardened case whose depth depends on process parameters. These paraequilibrium conditions pertain because the ratio of carbon to substitutional diffusivities is $10^{6}-10^{7}$.

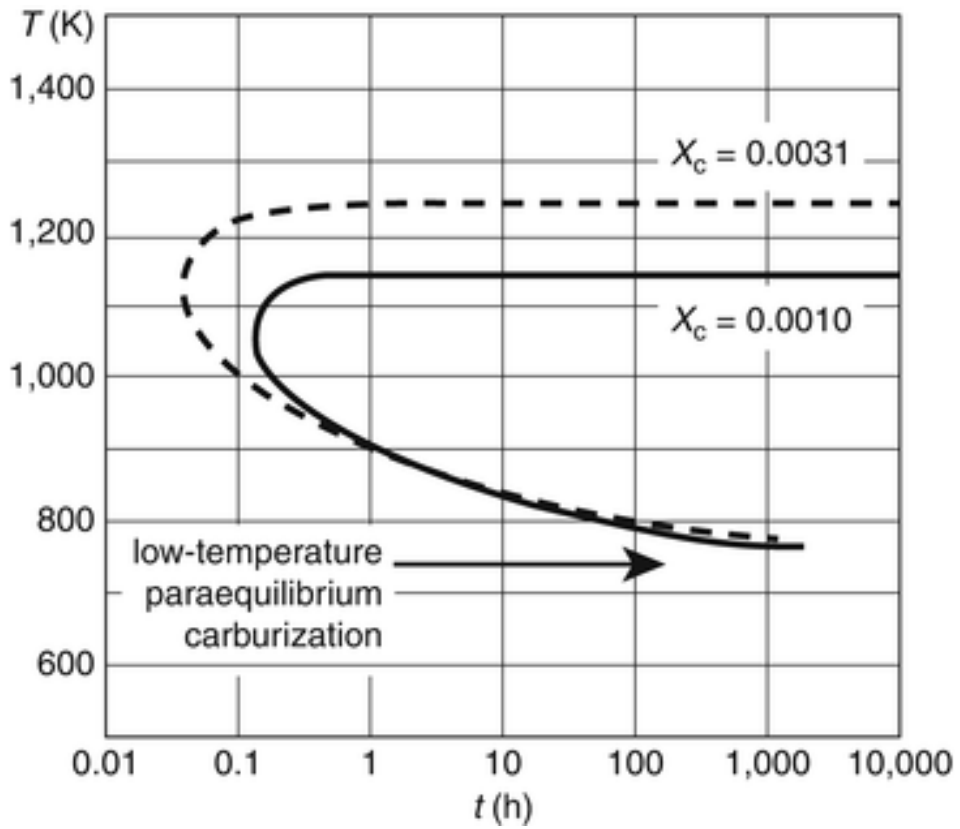

Low Temperature Carburization, Fig. 2 Time-temperature-transformation diagram for two 316 type stainless steel alloys illustrating how low temperature carburization kinetically limits carbide formation within the time of treatment (after Michal et al. (2006b)). The $X_{c}$

values are the carbon contents of the two steels

Because equilibrium carbides cannot form under these conditions, the extremely low equilibrium solubility of carbon is not relevant; rather, these carbide-forming elements lower the chemical activity of carbon, and result in metastable solubilities (>11 at. \% in $316 \mathrm{~L}$ austenitic stainless steel at $750 \mathrm{~K}$ ) many orders of magnitude greater than those achievable under 
thermodynamic equilibrium ( $\approx 2.1 \times 10^{-4}$ at.\%) (Michal et al. 2006b). This theoretical estimate is in good agreement with carbon levels measured by a variety of analytical techniques within the case-hardened region (Michal et al. 2006a, b; Sun et al. 1999; Aoki et al. 2001).

\section{Properties of Low Temperature Carburized Materials}

One of the most significant material property enhancements imparted by low temperature carburization is surface hardening (up to $12 \mathrm{GPa}$ ), which is directly related to the level of interstitial carbon dissolved within the stainless steel matrix (Fig. 3).

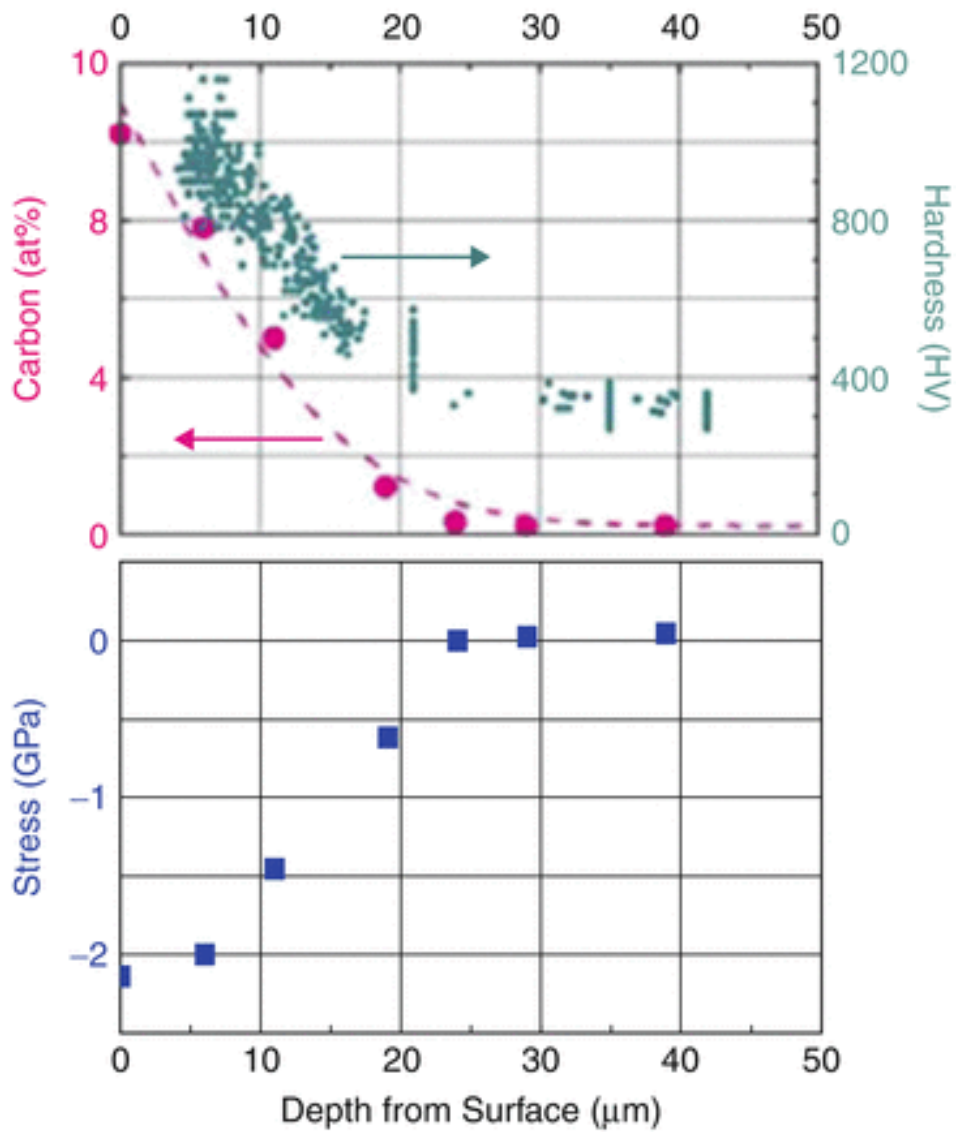

Low Temperature Carburization, Fig. 3 Carbon concentration, residual stress, and hardness depth profiles for low temperature carburized 316L (from Michal et al. (2006a))

Despite the massive hardening achieved by low temperature carburization, there is no attenuation of component ductility nor any evidence of embrittlement; profuse slip traces are present on the surface of tensile bars near their fracture surface (Michal et al. 2006a). TEM study of the material adjacent to the fracture surface revealed a high density of dislocations and deformation twins, further illustrating the good ductility of these interstitially hardened austenitic stainless steels.

During low temperature carburization, the "colossal" interstitial carbon content induces a significant lattice expansion, which can reach $3 \%$ or more in 316 L austenitic stainless steel (Fig. 3) (Michal et al. 2006a). Due to this lattice expansion, the case-hardened region is often referred to as "expanded austenite" (it is also referred to as "S-phase"). Inasmuch as free expansion of the carbon-rich diffusion layer is not possible because of the constraint offered by the untreated core, large bi-axial compressive stresses are generated within the case, >2 GPa for 316L (Agarwal et al. 2007) (Fig. 3), and enhance the high cycle fatigue resistance. These unique properties make low temperature interstitially hardened materials very attractive for use in many applications, particularly where a combination of good corrosion resistance and high hardness is needed.

\section{Key Applications}




\section{Corrosive Environment Applications}

Many highly corrosion resistant alloys are limited in their application by susceptibility to contact damage such as scratching, cavitation, or other forms of wear. Because low temperature carburization can harden the surface of these alloys without diminishing corrosion resistance, this process is ideal for improving the durability of corrosion-resistant materials that are subjected to contact stresses. In fact, improved corrosion resistance of carburized alloys in ambient temperature seawater involves nearly complete suppression of pitting corrosion.

\section{Improved Fatigue Resistance}

As mentioned above, low temperature carburization can be used to improve the fatigue behavior of stainless steel. Fully reversed $(R=-1)$ tensile-compressive fatigue tests of $316 \mathrm{~L}$ austenitic stainless steel have shown that low temperature carburization increases both the endurance limit and the fatigue lifetime at any stress (Agarwal et al. 2007). The improved fatigue resistance is a result of the residual compressive stresses within the surface regions of carburized materials effectively inhibiting surface nucleation of fatigue cracks during cyclic loading (Suresh 1998).

\section{Tribological Applications}

Low temperature carburized stainless steels (and interstitially hardened corrosion-resistant Ni-base alloys) are ideal for tribological applications, particularly when a corrosive environment is involved. The wear resistance and scratch resistance of interstitially hardened $316 \mathrm{~L}$ stainless steel is increased by one to two orders of magnitude in dry sliding and scratch tests at both room and elevated temperatures (up to $400^{\circ} \mathrm{C}$ ) (Qu et al. 2007a, b; O'Donnell et al. 2010). Self-mated carburized surfaces generally yield the best wear performance, although higher operating temperatures limit the extent of improvement. Even more significant wear reduction $(>1,000 \mathrm{X})$ has been observed in an oil-lubricated environment due to formation of a stable, anti-wear boundary film by tribochemical reactions between oil additives (e.g., ZDDP) and the carburized stainless steel surface. This surface treatment can be applied to various bearing components, such as bearings, gears, fittings, valves, guide rails, etc.

\section{Cross-References}

Carburizing and Carbonitriding

Kolsterising ${ }^{\circledR}$

\section{References}

- N. Agarwal et al., Enhanced fatigue resistance in $316 \mathrm{~L}$ austenitic stainless steel due to low-temperature paraequilibrium carburization. Acta Mater. 55, 5572 (2007)

- K. Aoki et al., Stainless Steel 2000 (Maney Publishing, London, 2001)

- E. Hall, C. Briant, Chromium depletion in the vicinity of carbides in sensitized austenitic stainless steels. Metall. Trans. A 15(5), 793 (1984)

- F. Martin et al., Carburization-induced passivity of $316 \mathrm{~L}$ austenitic stainless steel. Electrochem. Solid-State Lett. 10, 12-76 (2007)

- G.M. Michal et al., Carbon supersaturation due to paraequilibrium carburization: stainless steels with greatly improved mechanical properties. Acta Mater. 54, 1597 (2006a)

- G.M. Michal et al., Carbon paraequilibrium in austenitic stainless steel. Metall. Mater. Trans. A 37, 1819-1824 (2006b)

- L.J. O'Donnell et al., Wear maps for low temperature carburised 316L austenitic stainless steel sliding against alumina. Surface Engineering. 26(4), 284-292 (2010)

- J. Qu et al., Tribological properties of stainless steels treated by colossal carbon supersaturation. Wear 263, 719-726 (2007a)

- J. Qu et al., Effects of multiple treatments of low-temperature colossal supersaturation on tribological characteristics of austenitic stainless steels. Wear 265, 1909-1913 (2007b)

- Y. Sun, X. Li, T. Bell, J. Surf. Eng. 15, 49 (1999) 
- S. Suresh, Fatigue of Materials, 2nd edn. (Cambridge University Press, Cambridge, 1998)

- P. Williams et al., Swagelok company. Patent \# 6,093,303, 25 July 2000

- P. Williams et al., Patent \# 6,165,597, 26 Dec 2000

- P. Williams et al., Patent \# 6,461,448, 8 Oct 2002

- P. Williams et al., Patent \#6,547,888, 15 April 2003

\section{Low Temperature Carburization}

Prof. A. H. Department of Materials Science and Engineering, Case Western Reserve Heuer University, Cleveland, USA

Dr. Jun Qu Division of Materials Science and Technology, Oak Ridge National Laboratory, Oak Ridge, USA

L. O'Donnell Department of Materials Science and Engineering, Case Western Reserve University, Cleveland, USA

DOI: $\quad 10.1007 /$ SpringerReference_313148

URL: $\quad$ http://www.springerreference.com/index/chapterdbid/313148

Part of: $\quad$ Encyclopedia of Tribology

Editors: $\quad$ Prof. Q. Jane Wang and Prof. Yip Wah Chung

PDF created on:

August, 15, 2013 18:07

(C) Springer-Verlag Berlin Heidelberg 2013 